\title{
Atenção Humanizada ao Profissional da Saúde - Relato de Experiência
}

\author{
Oliveira, Patricia Gois de; Andrade, Maisa Alves; Almeida, Thaynara Fontes; \\ Fontes, Mírzia Lisboa; Menezes, Andreia Freire; Araujo, Jamilly Santos \\ Universidade Tiradentes _ mlf_mlf@hotmail.com
}

INTRODUÇÃO: Os Trabalhadores são expostos a algum tipo de estresse em seus ambientes de trabalho. Isso os possibilitam alguma alteração de desempenho no trabalho, que geralmente constitui na piora e no adoecimento dos profissionais. Quando se fala de humanização a primeira pessoa lembrada é o paciente, entretanto o ministério da saúde em seu programa nacional de humanização da assistência hospitalar (PNHAH) traz que, deve-se unir a técnica e o conhecimento cientifico respeitando a singularidade de cada paciente e profissional, aceitando os limites de cada situação, ou seja, deve-se respeitar o todo e não apenas o usuário. OBJETIVO: Relatar a experiência vivida com profissionais da saúde a fim de diminuir o estresse no ambiente de trabalho. METODOLOGIA: Trata-se de um relato de experiência desenvolvido durante uma atividade com profissionais da saúde no dia do servidor público em uma instituição de ensino Federal de Sergipe no município de Lagarto. Cerca de 30 profissionais participaram da atividade proposta. As atividades desenvolvidas no stand da enfermagem foram a avaliação do nível de estresse dos servidores e a massoterapia. RESULTADOS: Após uma palestra sobre a saúde do trabalhador, os profissionais foram encaminhados para um espaço que continham vários stands cada um com temas e ações diferentes. no stand da enfermagem os profissionais responderam a um questionário que através da sua pontuação foram avaliados quanto ao seu nível de estresse, em seguida, receberam orientação de uma massoterapeuta sobre algumas atividades que podem ser realizadas no ambiente de trabalho para torná-lo mais agradável como por exemplo: a utilização de músicas de relaxamento, sentar de formar mais correta e realizar troca de massagens com outros colegas do trabalho. Após algumas orientações, a massoterapeuta juntamente com alguns alunos do curso de enfermagem demonstraram técnicas de massagem que pudessem ser utilizadas no ambiente de trabalho entre colegas. com isso, os trabalhadores puderam praticar entre si. CONCLUSÃO: Estratégias adequadas para tornar o trabalho um ambiente mais tranquilo e menos estressante favorecem a melhora do fornecimento da atenção aos pacientes e a prevenção de doenças ocupacionais. Desse modo, percebe-se que se faz necessário o desenvolvimento de estratégias favoráveis às condições do trabalhador.

Oliveira, Patricia Gois de; Andrade, Maisa Alves; Almeida, Thaynara Fontes; Fontes, Mírzia Lisboa; Menezes, Andreia Freire; Araujo, Jamilly Santos. Atenção Humanizada ao Profissional da Saúde - Relato de Experiência. In: Anais do Congresso Internacional de Humanidades \& Humanização em Saúde [= Blucher Medical Proceedings, num.2, vol.1]. São Paulo: Editora Blucher, 2014. ISSN 2357-7282 DOI $10.5151 /$ medpro-cihhs-10784 